\title{
TRANSFER OF TRAINING AND JOB PERFORMANCE: ANALYSIS OF DEVELOPMENT SECTOR IN PAKISTAN
}

\section{Salima Shahin ${ }^{*}$ and Kamran Ahmed Soomro²}

\begin{abstract}
The purpose of this research is to examine the relationship between training factors and job performance when training transfer mediates the relationship. This research is quantitative in nature and has employed SPSS-21 and Smart-PLS software to analyze the data and to test the hypothesized relationship between variables of the conceptual model. The research strategy involves a survey design using primary data. The findings of the research indicated a strong positive relationship between latent constructs. Moreover, the direct relationship between training factors and training transfer was significant therefore hypotheses were accepted. The indirect relationship between training transfer and job performance was significant and positive therefore hypotheses involved were accepted. The findings of the research under the study supported existing literature. Managerial implications of the research involve staff preparedness that should be ensured by working proactively, training aims should be associated with the organizational goals, and the relevance of training content should be ensured with the current job. This study enriched the understanding of the gap between training received and implications on the development sector by showing the impact of training factors and training transfer on job performance.
\end{abstract}

Keywords: Job Performance; Work Environment; Training Transfer; Training Design.

\section{INTRODUCTION}

Organizations as a part of a global economy are facing dynamic challenges; one of the best ways to cope with the challenges brought by the environmental change is to improve the skills, knowledge and abilities of employees (Marr, 2017). Employees possess varied skills and unique

\footnotetext{
${ }^{1}$ Lecturer, Faculty of Management Sciences, Karakoram International University, Gilgit Baltistan, Pakistan. Email: salima@kiu.edu.pk

${ }^{2}$ Assistant Professor, Faculty of Management Sciences Shaheed Zulfiqar Ali Bhutto Institute of Science and Technology, Karachi, Pakistan. Email: dr.kamran@ szabist.edu.pk

*Corresponding Author
} 
in-built competencies which need to be enhanced and polished. In this essence, it is inevitable for organizations to intervene with the professional skill development programs through trainings. Literature suggests that trainees are unable to transfer learning that comes from the training to the actual workplace involving many factors.

Employees are considered an important asset in the organization. They are a source of sustained competitive advantage. A firm can act successfully and be competitive in the market by developing its employees' skills, knowledge and ability. (Obaid, 2014). Using tools, firms today are analyzing internal and external environments to understand the sources of sustained competitive advantage. Employee productivity can be improved by motivating them well in diverse ways. Training is one of the ways by designing it for their respective job. Employees apply learned skills and knowledge at the workplace. Often, the barriers to transfer occur before, during and after learning intervention. Therefore learning from training is not transferred to the workplace. Transfer of training is the execution at the workplace of what is learned in a specific period of time (Starks, 2019). Baldwin and Ford (1998) identified transfer problems in training research, where recommendations were provided on maximizing the gap between learning and continued performance. The usefulness of training activities and details about how it is causing effective outcomes at the individual, group and organizational level has been examined by many researchers but few studies involve the actual transfer of learning that comes from training at the workplace. Transfer of learning has positive outcomes.

Job performance is considered an outcome because it can be achieved as a result of a certain behaviour (Siddiqui \& Iqbal, 2021; Pandey, 2019). The organizations are investing in training and development to enhance individuals' competencies and expecting them to give the required output (Na-Nan \& Sanamthong, 2019). Moreover, the basic aim of training investment is to achieve positive outcomes like job performance by ensuring the transfer of learned skills on the job. The effectiveness of training is measured using the transfer of training at the workplace (Shi \& Liu, 2015). Enterprises are successful when they are able to measure the transfer of learning that comes from training at the workplace, providing the outcomes of improved individual and organizational performance. A change at the organizational, group and individual level is the definition of learning outcome (Turi et al., 2019).

This research is conducted in the development sector. Humanitarians bring the change in the normal behavioural pattern of the people by fulfilling their basic needs of food, shelter etc. and providing aid to the people in unfortunate situations. Humanitarian organizations have 
collaborative networks operating locally as well as at global levels. Stockholders involved in humanitarian operations are agencies of the United Nations and NGOs. The core point in selecting these organizations is that they are working for the capacity building of employees by providing extensive trainings to their diverse workforces. Hence, the transfer of training and its impact on workplace outcomes can be analyzed based on the past or current training experience of the employee.

The purpose of this research is to analyze the effect of identified factors of training on the transfer of learning (training) that comes from the training at the workplace that leads to job performance. However, learning transfer, in the long run, has demonstrated poor results towards optimistic performance outcomes (Starks, 2019). Moreover, the mediating relationship of transfer of training between training factors and job performance is analyzed. The employee conduct or behaviour in the context of a certain job-related task is job performance (Fogaça et al., 2018).

\section{STATEMENT OF THE PROBLEM}

Over the last two decades, organizations have been focusing on human resource development (HRD) by investing in professional development and training programs. The main objective of these programs is to improve employee skills, knowledge and abilities towards the achievement of a specific job and organizational outcomes. However, past trends suggest a poor application of learned skills towards the achievement of objectives. Therefore, without proven results organizations are least concerned to invest in HRD programs. It is a challenge for HRD professionals to design effective training programs that ensure learned knowledge at the workplace, to achieve desired outcomes.

The research under the study is focused on the development sector where stockholder organizations are involved in the capacity building of their manpower by providing extensive training programs. Employee responses are taken to analyze the mediating role of training transfer in the relationship between training factors and workplace job performance. Organizations' are investing huge amounts of money in trainings to get the desired outcomes. Out of this training investment, only a smaller percentage resulted in desired outcomes. Therefore the transfer of learning that comes from the training is considered a training problem that needs to be sorted out (Blume, Ford, Baldwin, \& Huang, 2010). Firms wanting to improve investment in trainings and get the desired outcomes, need to pinpoint and develop factors that cause the transfer of learning at the workplace (Friedman \& Ronen, 2015). Training transfer is considered as a measure of 
training effectiveness (Shi \& Liu, 2015), therefore firms are focusing on evaluating the transfer of training at the workplace because this factor leads to organizational success. The problem arises when employees are unable to transfer training at the workplace to get the desired outcomes. Thus, it is important to know how training transfer is playing a role to get the desired job performance outcomes.

This study intends to analyze how training factors lead to training transfer at the workplace and consequently how it leads to job performance. Besides, the direct impact of training factors (individual characteristics, training design and work environment) on training transfer and the indirect impact of training factors on job performance when training transfer mediates the relationship will be analyzed.

\section{RESEARCH OBJECTIVES}

Through the review of literature, the following research objectives could be drawn.

1. To analyze the effect of trainee characteristics, workplace environment and training design factors on training transfer and the extent to which each factor contributes to training transfer.

2. To analyze the mediating impact of training transfer in the relationship between training factors (individual characteristics, work environment and training design) and job performance.

\section{RESEARCH QUESTIONS}

RQ1: What is the Impact of trainee characteristics, workplace environment and training design factors on training transfer?

RQ2: What is the impact of training factors (individual characteristics, work environment and training design) on job performance when training transfer mediates the relationship?

\section{LITERATURE REVIEW}

\section{Training Transfer Overview}

The additional experience in a new situation is measured as the transfer of training (Kilbrink et al., 2018). Transfer of training is one of the core factors to improve employee competencies and professional skills, however desired outcomes cannot be attained due to challenges arising (Starks, 2019). Various factors hinder the process of transfer of training, from training, received to the achievement of organizational objectives. Irrespective of constraints in the transfer of training, employees should perform efficiently to achieve sustained competitive advantage (Ma \& Chang, 2013). The training research has moved beyond training effectiveness to the successful training 
transfer (Bai, li, Bai, \& Ma, 2018). The effectiveness of the transfer of training depends upon the self-efficacy of the trainee, pre-training motivation, the extent of learned capability out of a training session and transfer of that capability to the workplace (Ma \& Chang, 2013). Literature suggests that trainees learned skills in the training are transferred only up to 10 to 20 percent (Ma \& Chang, 2013).

According to Bukar and Ibrahim (2021), the success of a training program depends on the two perspectives, educational and economic, where educational perspective is providing a learning environment to enhance individual knowledge and competencies while educational perspectives are related to the application of learned skills to the workplace. Transfer of training is a concept based on an economic perspective.

\section{Themes in the Transfer of Training}

Baldwin and Ford (1988) presented a model of transfer of training consisting of input factors, output factors and conditions of transfer. Baldwin and Ford's (1988) model have enhanced the understanding of the concept of transfer of training (Grossman \& Sales, 2014). This model suggests certain factors to be considered in the process of transfer of training to get the desired outcomes, involving trainee characteristics, training design factors and work environment factors (Starks, 2019). Input factors indicate the expectations and experience of trainees from a training program (Leornardo, 2015)

The transfer is the third level in Kirkpatrick's (2011) model of training evolution which is most applicable to assess transfer of training based on trainee's performance and to equate training input factors with outcomes (Starks, 2019). Further, this level demonstrates the confirmation of the achievement of the first two levels of reaction and learning, therefore, it provides a realistic picture to management about the skills, knowledge and abilities needed to ensure transfer.

\section{Job Performance}

Job performance represents the task yield of an organization, individual or a group (Na-Nan \& Sanamthong, 2019). Further, the organization expects individuals to deliver expected output where employee potential is enhanced through heavy investments in training and development. Employee job performance refers to the conduct established by the employer to meet organizational goals (Fogaça et al., 2018). Moreover, job performance is employee conduct or behaviour in the context of a certain job-related task. 
Two aspects of job performance are mentioned in the literature, behavioural and outcome perspectives. The behavioural approach is related to the performance of given job-related tasks, whereas the outcome aspect is viewed as a result of that behaviour (Pandey, 2019).

\section{Influence of Individual Characteristics on the Transfer of Training}

Research studies in organizational training fall into one of three categories (Leonardo, 2015). The research under the study is focused on individual characteristics of self-efficacy and training retention. According to Grossman and Sales (2014), training utility, self-efficacy and intellectual ability have a strong association with the transfer of training. Trainee characteristics and trainee attributes play an important role while transferring the learned skill from the training to the workplace (Saleh, 2011). The above given evidence leads the study to suggest that:

H1: There is a significant positive relationship between individual characteristics and training transfer.

\section{Influence of Workplace Environment Factors on Transfer of Training}

This research involves certain work environment factors such as supervisor support and opportunity to use. These factors can encourage the transfer of training. According to Bhatti et al. (2013), supervisor support is a core element to bring training success by transfer of training Supervisor's support as a work environment factor can be in the form of per and post-training, support related to training material and passionate support (Putter, 2013). Supervisors involved in training need identification for employees by pinpointing progress areas and motivating employees to be a part of a training program and applications of learned skills at the job (Qureshi \& Hamid, 2017). The impact of organizational factors on the transfer of training and its outcomes in terms of supervisor support and feedback is hypothesized in this study. Kia \& Ismail (2013) investigated and proved the relationship between training transfer and all dimensions of the work environment. The given the study to suggest that:

H2: There is a significant positive relationship between work environment factors and training transfer at the workplace.

\section{Influence of Training Design Factors on Transfer of Training}

Training design must be compatible with the job requirements to achieve positive workplace outcomes. Transfer of learning is dependent on resemblance and dissimilarity of contents and conditions of the learning environment and actual job. Further, it depends upon the learning 
process (Kilbrink et al., 2018). More knowledge of job content leads to increased interest in the performance of daily tasks (Ellstrom \& Ellstrom, 2014). Bhatti et al. (2013) researched training design factors that play role in the process of training. Self-efficacy plays a mediating role in training designed factors and transfer motivation (Fatima \& Siddiqui, 2019). The transfer must be compatible with the job requirements to achieve positive workplace outcomes. Motivation and self-efficacy are important factors in training design that provokes an employee to transfer the learned skills on the job (Bhuiyan et.al, 2017). Based on the given knowledge following can be hypothesized:

H3: There is a significant positive relationship between training design factors and training transfer to the workplace.

\section{Influence of training transfer on Job performance}

Transfer of training is defined as the extent to which the participant of the training acquires a sustained change in the way work is performed due to the change in skill knowledge and ability (Wenzel \& Cordery, 2014). Training leads to improved self-confidence and competence level, more knowledge of job content that leads to increased interest in the performance of daily tasks. Training has improved employees' problem-solving ability and critical analysis, assumed more responsibility to perform their job than before, improved work methods (Ellstrom \& Ellstrom, 2014). Transfer learning leads to two outcomes individual workplace learning outcomes and organizational learning outcomes, where the prior involve improved competence and confidence with the motivational and desire to learn, development of leadership and management skills and the latter involve two main themes of enhanced professional practice and organizations gain, being able to integrate HRM with organizational strategy (Crouse, Doyle, \& Young, 2011). Based on it is hypothesized as below:

H4: There is a significant positive relationship between training transfer and job performance.

\section{Influence of Trainee Characteristics on Job Performance when Training Transfer Mediates the Relationship}

The findings of the study confirm the significant relationship between cognitive and behavioural changes with company performance (Dermol \& Čater, 2013). Based on the Baldwin and Ford model (1988), trainee characteristics (individual factors) involve self-efficacy; motivation and cognitive ability are impacting training transfer (Grossman \& Sales, 2014). According to 
Bhuvanaiah \& Raya (2015) employees obtain motivation to transfer the learned skills at the workplace from the manager, immediate boss and self-motivation. When the employee is motivated to transfer, it leads to training transfer at the workplace (Kim-Soon et al, 2014). Job performance is considered an outcome because it can be achieved as a result of a certain behaviour (Pandey, 2019). The given evidence leads the study to suggest that:

H5: There is a significant relationship between trainee characteristics and job performance when training transfer mediates the relationship.

\section{Influence of Work Environment on Job Performance when Training Transfer Mediates the Relationship}

Skills and knowledge gained after training cannot be transferred to the workplace even after having a strong training design in the absence of a conducive work environment (Grossman \& Sales, 2014). Work environment factors involve supervisory and peer support, opportunities to apply skills, and workplace climate. Learned skills and knowledge will be immaterial and elapsed if management will not prove a supportive work environment (Obaid et al., 2016). Successful transfer of training leads to professional development, improved skill knowledge and ability, and improved employee retention (Bai, li, Bai, \& Ma, 2018) Based on the above literature, the following assumption can be hypothesized:

H6: There is a significant relationship between work environment and job performance when training transfer mediates the relationship.

\section{Influence of Training Design on Job Performance when Training Transfer Mediates the Relationship}

Training design involves training design, method and trainer skills to enable trainees to acquire and transfer skills at the workplace (Alias, Ong, Rahim, \& Hassan, 2019). Further training competence is found the greatest contributor in achieving training goals. Training design is an important element in the transfer process and consequently in achieving positive learning outcomes (Grossman \& Sales, 2014). Ghosh et al. (2012) found a connection between training contents and achieving positive organizational outcomes. Job performance with reference to behavioural and outcome perspective is elaborated as a positive organisational outcome Pandey (2019). Therefore, the intention of the study based on the given argument above is to test the following:

H7: There is a significant relationship between training design and job performance when transfer training mediates the relationships. 


\section{CONCEPTUAL FRAMEWORK}

The conceptual model in figure 1 is formed based on the themes in the transfer of training and empirical review.

Table 1. Empirical Review

\begin{tabular}{|c|c|c|}
\hline Variable & Author & Description \\
\hline \multirow[t]{5}{*}{ Training Transfer } & $\begin{array}{l}\text { (Kilbrink et al., } \\
\text { 2018) }\end{array}$ & The additional experience in a new situation is measured as a transfer of training. \\
\hline & (Starks, 2019) & $\begin{array}{l}\text { Transfer of training is the execution at the workplace of what is learned in a } \\
\text { specific period of time. }\end{array}$ \\
\hline & $\begin{array}{l}\text { (Ma \& Chang, } \\
\text { 2013). }\end{array}$ & $\begin{array}{l}\text { The effectiveness of the transfer of training depends upon the self-efficacy of the } \\
\text { trainee, pre-training motivation, the extent of learned capability out of a training } \\
\text { session and transfer of that capability to the workplace. }\end{array}$ \\
\hline & $\begin{array}{l}\text { (Bukar \& } \\
\text { Ibrahim, 2021) }\end{array}$ & $\begin{array}{l}\text { The success of a training program depends on the two perspectives, educational } \\
\text { and economic }\end{array}$ \\
\hline & (Alton, 2017) & $\begin{array}{l}\text { Defined one kind of transfer as a transfer from learning to application. The other } \\
\text { two kinds of training transfers; transfer from old learning to new learning and } \\
\text { transfer from previous understanding of knowledge to new learning. }\end{array}$ \\
\hline \multirow{4}{*}{$\begin{array}{l}\text { Training Factors } \\
\text { (Individual } \\
\text { Characteristics) }\end{array}$} & (Leonardo, 2015) & $\begin{array}{l}\text { Research in organizational training falls into one of these three categories: input, } \\
\text { output, and maintenance factors. }\end{array}$ \\
\hline & $\begin{array}{l}\text { Grossman \& } \\
\text { Sales (2014) }\end{array}$ & $\begin{array}{l}\text { The training utility, self-efficacy and intellectual ability have a strong association } \\
\text { with the transfer of training. }\end{array}$ \\
\hline & (Ford, 2009). & $\begin{array}{l}\text { Individuals' post-training willingness to learn has a strong impact on training } \\
\text { transfers. }\end{array}$ \\
\hline & (Bhatti, 2010) & $\begin{array}{l}\text { Rules of transfer, conditions of transfer and stimulus change has an impact on } \\
\text { TOT. }\end{array}$ \\
\hline \multirow[t]{5}{*}{$\begin{array}{l}\text { Work } \\
\text { Environment }\end{array}$} & $\begin{array}{l}\text { Bhatti et al. } \\
\text { 2013) }\end{array}$ & $\begin{array}{l}\text { Supervisor support is a core element in bringing training success through the } \\
\text { transfer of training }\end{array}$ \\
\hline & (Çifci, 2014) & $\begin{array}{l}\text { A conducive work environment leads to positive transfer of learned skills on the } \\
\text { job. }\end{array}$ \\
\hline & (Leonardo, 2015 & $\begin{array}{l}\text { Input factors indicate the expectations and experience of trainees out of a training } \\
\text { program. }\end{array}$ \\
\hline & $\begin{array}{l}\text { Curry et al. } \\
(2005)\end{array}$ & $\begin{array}{l}\text { Only } 34 \% \text { is transferred after a year of training received, } 44 \% \text { after six months } \\
\text { and } 64 \% \text { transferred immediately after a training program. }\end{array}$ \\
\hline & $\begin{array}{l}\text { (Qureshi \& } \\
\text { Hamid, 2017) }\end{array}$ & $\begin{array}{l}\text { Training requires identification for the employee by pinpointing progress areas } \\
\text { and motivating the employee to be a part of a training program and applications } \\
\text { of learned skills at the job }\end{array}$ \\
\hline \multirow[t]{2}{*}{ Job Performance } & $\begin{array}{l}\text { (Na-Nan \& } \\
\text { Sanamthong, } \\
\text { 2019). }\end{array}$ & Job performance represents the task yield of an organization, individual or group. \\
\hline & $\begin{array}{l}\text { (Fogaça et al., } \\
\text { 2018) }\end{array}$ & $\begin{array}{l}\text { Job performance is affected by various factors such as individual's characteristics, } \\
\text { work environment, organizational environment. }\end{array}$ \\
\hline
\end{tabular}


Table 2. Themes in Transfer of Training

\begin{tabular}{|c|c|c|c|}
\hline Theory & Author & Explanation & Study Relevance \\
\hline $\begin{array}{l}\text { Baldwin and Ford } \\
\text { (1988) Model }\end{array}$ & $\begin{array}{l}\text { Baldwin and } \\
\text { Ford }\end{array}$ & $\begin{array}{l}\text { Consists of input factors, } \\
\text { output factors and } \\
\text { conditions of transfer. }\end{array}$ & $\begin{array}{l}\text { Three components of training input, training output } \\
\text { and maintenance where trainee (individual) } \\
\text { characteristics, training design and work } \\
\text { environment factors are subcategories of training } \\
\text { input factors (Çifci, 2014). }\end{array}$ \\
\hline $\begin{array}{l}\text { Training evolution } \\
\text { model (1993) }\end{array}$ & Kirkpatrick & $\begin{array}{l}\text { Involve reaction, learning, } \\
\text { transfer and results. }\end{array}$ & $\begin{array}{l}\text { Most applicable to assess the transfer of training } \\
\text { based on trainee's performance and to equate training } \\
\text { input factors with outcomes (Starks, 2019). }\end{array}$ \\
\hline $\begin{array}{l}\text { learning transfer } \\
\text { system (LTSI)( } \\
\text { 2000) }\end{array}$ & Holton III & $\begin{array}{l}\text { Theoretically based, a } \\
\text { generalizable instrument to } \\
\text { be used in diagnosing an } \\
\text { organization's strengths } \\
\text { and weaknesses for } \\
\text { learning transfer }\end{array}$ & $\begin{array}{l}\text { Suggest certain factors to be considered in the } \\
\text { process of transfer of training to get the desired } \\
\text { outcomes, involving trainee characteristics, training } \\
\text { design factors and work environment factors (Starks, } \\
2019 \text { ). }\end{array}$ \\
\hline $\begin{array}{l}\text { Principle of identical } \\
\text { elements(1901) }\end{array}$ & $\begin{array}{l}\text { Woodworth } \\
\& \text { Thorndike }\end{array}$ & $\begin{array}{l}\text { Explains the positive } \\
\text { correlation between the } \\
\text { similarities between } \\
\text { training and performance } \\
\text { environments and the level } \\
\text { of training transfer. }\end{array}$ & $\begin{array}{l}\text { Explains the relationship between training } \\
\text { performance environment and training transfer. }\end{array}$ \\
\hline
\end{tabular}

Figure 1. Conceptual Model

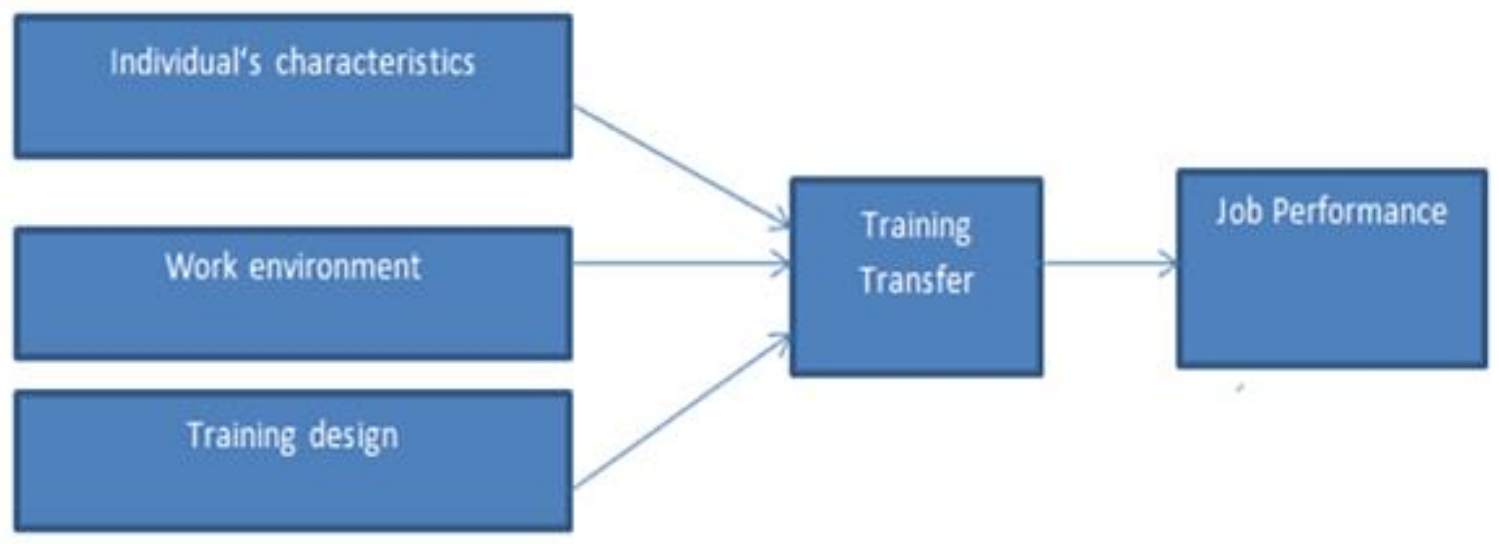

Adopted from: Baldwin and Ford (1988); Velada et al. (2007); Obaid et al. (2016)

The basic argument of the research under study involves the investigations of the mediating effect of transfer of training in the relationship between training factors and job performance. This model sketches three elements as training factors are, trainee characteristics, training design and work environment leading to training transfer and job performance. These factors are vital to achieving organizational outcomes and individual ability (Grossman \& Sales, 2014). Therefore, this model is relevant to the research under study. Moreover, trainers are unable to maximize individuals' 
ability due to wrong utilization and application of training concepts, therefore this model provides authentic and proven elements that lead to training transfer in different contexts.

This study is based on the principle of identical elements suggested by Woodworth and Thorndike (1901) that elaborates the relationship between two elements, training and performance environment, and transfer of training. Further, these elements should be similar to ensure the successful transfer of training to the workplace. According to identical elements theory, successful transfer of learning is possible when the components of two settings are alike (Tracey \& Mandel, 2012).

\section{METHODOLOGY}

\section{Research Approach}

According to Bell et al. (2018), there are two approaches to research, deductive and inductive, where the research approach describes the relationship between existing theory and the research. The research approach involves thorough suppositions regarding the data gathering method, analysis, and interpretation. The study involves a deductive research approach based on Baldwin and Ford (1998) model showing the relationship between transfer factors and transfer of training at the workplace. This research investigated the mediating role of transfer of training in the relationship between transfer factors and transfer outcomes.

\section{Research Type}

Descriptive, exploratory, and explanatory are three different types of research (Saunders et al., 2009). The study is quantitative in nature thus is explanatory. This research intends to explain the causal relationship between latent construct of transfer factors, training transfer and job performance, thus qualifies as being an explanatory research

\section{Research Strategy}

The research strategy is the general plan for answering the research questions that involve researchers philosophical understanding and research objectives, the existing knowledge and the amount of time and other resources available (Saunders et al., 2009), elaborates researches strategies involve experiments, surveys, case study, action research, grounded theory, ethnography and archival research. Since this research is a quantitative study, the analysis is done based on the survey using primary data from the employees working in different organizations. 


\section{Research Method}

Under the research method, based on the research question, the collection of data and its analysis is prepared by the researcher. This research is conducted using a quantitative method where primary data analysis is done using a questionnaire from different employees working in various organizations.

\section{Sampling and Selection Technique}

A sample is the smaller portion of the total population under analysis (Polit \& Beck, 2010). It is important to obtain and generalize information regarding all cases out of which samples are drawn (Saunders et al., 2009). Further, collecting information from a large number of cases enables the researcher to get an accurate and detailed view of the phenomena under study. A sample is selected based on the precision of the sample and disparity in population. According to Hair et al. (2010), a larger sample size increases precision and variation.

The total population is unknown therefore this research is conducted based on the snowball sampling strategy on employees working in NGOs located in Karachi involving local NGOs, national and international NGOs including all Karachi based agencies of the United Nations Organization with the sample slide of 253 , where initially 500 questionnaires were distributed manually and sent using Google docs. The first justification for sample size is resource constraints. Because of lack of time and lack of a proper database in the development sector, data was collected on the basis of convenience. The second justification is accuracy where the desired level of data was collected to achieve significant results. Online data for the research under the study is collected due to the COVID situation. The inclusion criteria for the target sample were made based on the following points:

- The sample comprised only employees of NGOs working in Karachi.

- Sample choice was based on the assumption that employees have prior job-relevant training experience.

- Inclusion of only those employees who are willingly responding and interested in participating.

- There will be no monetary benefits paid to the respondents.

\section{Analytical Techniques}

This is a quantitative study where descriptive statistics were conducted using SPSS version 21. The research type of the study is explanatory where causal effect between variables is involved 
therefore using PLS version 3.0 by Ringle and Wende. and., Becker (2015) was employed to analyze the validity, reliability and for confirmatory factor analysis and hypothesis testing.

Data were analyzed using Partial Least Square-Structural Equation Modelling (PLS-SEM) to understand the relationship between constructs and the indicators (Nitzl et al., 2016). The research under study involve a mediator, therefore the mediation effect (indirect effect) was analyzed through bootstrapping to know the size of mediation. The mediating effect occurs when the third variable affects the relationship between the dependent and independent variables (Nitzl et al., 2016). The analysis was performed using Baron and Kenny 1986 approach.

\section{Structural Equation Modeling}

The structural equation model (SEM) analyzes multiple variables from primary sources (questionnaire, interviews) and secondary sources (secondary database) (Carrion, Navarro, \& Cillo, 2019). Moreover, this method is a blend of regression analysis and factor analysis that emphasizes the predictive capability of the model. There are two types of SEM: PLS-SEM and CB -SEM. PLS assesses multifaceted associations amongst the constructs. According to Rigdon et al. (2019), the main focus of PLS-SEM is to maximize variance (R2) in the endogenous variable in the path model.

\section{Data Collection Methods and Sources}

Using Google Docs, a survey questionnaire link was sent to the respondents, where responses were self-administered. The quantitative analysis involves data collection from 253 randomly selected respondents. The frequency of the response will be categorized based on the research objectives and research questions. The respondents of this research are employees of humanitarian and development sector organizations, involving diversified employees, where extensive training is offered. Therefore, each employee is assumed to have training experience. Around 350 respondents were approached initially using snowball sampling strategy where the unit head was approached by sending an email that directs a link and asked to invite interested participants by sending the link to give their responses. All participants were volunteers so they were not provided with any kind of monetary compensation for survey instrumentation.

For the purpose of collecting primary data, a self-administered questionnaire was used. The participants were asked to score responses five-point Likert scale ranging from 1 (strongly agree) 
to 5 (strongly Disagree). The table below represents the sources of constructs along with the number of items. Moreover, the constructs and related indicators are given in the appendix.

Table 3. Summary of Measurement Scales

\begin{tabular}{llc}
\hline Measures & Authors & No. of Items \\
\hline Individual Characteristics & Velada et al. (2007), Holton and Baldwin (2003) & 5 \\
Work Environment & Velada et al. (2007), Holton and Baldwin (2003) & 5 \\
Training Design & Velada et al. (2007), Holton and Baldwin (2003) & 5 \\
Training Transfer & Velada et al. (2007), Holton and Baldwin (2003) & 3 \\
Job Performance & Jackson (2014), Goodman and Svyantek (1999) & 8 \\
\hline
\end{tabular}

\section{Pilot Study}

\section{RESULTS AND DISCUSSION}

Using Google docs, 70 questionnaires were distributed to the respondents who were meeting the preset selection criteria. Out of the 70 questionnaires, 53 were returned suggesting necessary changes in the questionnaire description by a few respondents. Results of the reliability statistics are shown in Table 4 below.

Table 4. Reliability Statistics of Pilot Study

\begin{tabular}{lcc}
\hline Categories & Cronbach's Alpha & No. of Items \\
\hline Overall & 0.973 & 25 \\
Individual Characteristics' & 0.942 & 5 \\
Work environment & 0.906 & 5 \\
Training Design & 0.841 & 4 \\
Transfer training & 0.913 & 3 \\
Job performance & 0.967 & 8 \\
\hline
\end{tabular}

\section{Sample Size Adequacy}

Kaiser-Meyer-Olkin (KMO) and Barlett's test of sphericity indicated a portion of the variance in variables caused by factors. It is used to check the appropriateness of the sample for the study under investigation. The assumptions of this test include p-value should be less than 0.05 and the KMO measure of sampling adequacy should be higher than 0.60 to shoe the sufficient items for each factor (Zhu, 2018). Table 5 confirms both assumptions of the test by showing a p-value of 0.000 at a significant level less than 0.05 and KMO sample adequacy of 0.958 at a value higher than 0.06. Hence, the size of sample 353 is appropriate for the phenomena user investigation. 
Table 5. KMO and Barlett's Test

\begin{tabular}{lll}
\hline \multicolumn{2}{l}{ Kaiser-Meyer-Olkin Measures of Sampling Adequacy. } & .958 \\
& Approx. Chi-Square & 4481.883 \\
Bartlett's Test of Sphericity & Df & 300 \\
& Sig. & .000 \\
\hline
\end{tabular}

\section{Respondents Demographics}

Table 6 below represents SPSS results showing variability in respondents demographics involved, organization, management level, and years of service and training experience. Moreover, the sample size iinvolves $78 \%$ male respondents and $22 \%$ female respondents out of a total sample of 253. The population of this study is the development sector so $17 \%$ international NGO respondents and $30 \%$ National respondents with $21 \%$ employees of United Nations agencies and 31\% from other areas of the development sector.

Table 6. Respondents Demographics

\begin{tabular}{|c|c|c|c|}
\hline Items & & Sample & Percentage \\
\hline \multirow[t]{3}{*}{ Gender } & Female & 60.0 & 23.7 \\
\hline & Male & 193.0 & 76.3 \\
\hline & Total & 253.0 & 100.0 \\
\hline \multirow[t]{6}{*}{ Age } & $18-21$ & 1.0 & 0.4 \\
\hline & $18-29$ & 52.0 & 20.6 \\
\hline & $30-45$ & 145.0 & 57.3 \\
\hline & $46-60$ & 54.0 & 21.3 \\
\hline & 58 years & 1.0 & 0.4 \\
\hline & Total & 253.0 & 100.0 \\
\hline \multirow[t]{5}{*}{ Organization } & International NGO & 42.0 & 16.6 \\
\hline & UN Agency & 56.0 & 22.1 \\
\hline & National NGO & 71.0 & 28.1 \\
\hline & Others & 84.0 & 33.2 \\
\hline & Total & 253.0 & 100.0 \\
\hline \multirow[t]{5}{*}{ Management Level } & Director & 29.0 & 11.5 \\
\hline & Executive Director & 7.0 & 2.8 \\
\hline & Manager & 89.0 & 35.2 \\
\hline & Officer & 128.0 & 50.6 \\
\hline & Total & 253.0 & 100.0 \\
\hline \multirow[t]{5}{*}{ Years of Service } & 1 to 10 years & 140.0 & 55.3 \\
\hline & 11 to 20 years & 85.0 & 33.6 \\
\hline & 21 t0 30 years & 21.0 & 8.3 \\
\hline & 30 years and above & 7.0 & 2.8 \\
\hline & Total & 253.0 & 100.0 \\
\hline \multirow[t]{6}{*}{ How often do u undergo trainings? } & 2. Quarterly & 53.0 & 20.9 \\
\hline & 3. Half yearly & 52.0 & 20.6 \\
\hline & 4. Once a year & 84.0 & 33.2 \\
\hline & 5. Every two years & 36.0 & 14.2 \\
\hline & Every month & 28.0 & 11.1 \\
\hline & Total & 253.0 & 100.0 \\
\hline
\end{tabular}




\section{Reliability Testing}

The questionnaire was adapted from several sources data was then collected and analyzed using PLS-SEM to find Confirmatory Factor Analysis (CFA) and to identify the goodness of fit between data and hypothesized model. This method is used only when the investigator has a prior understanding of the core underlying variables (Byrne, 2010). According to Nor Azman (2017), the primary aim of using confirmatory factor analysis is to confirm hypothesized relationships and to authenticate measurement models. Table 7 below indicates that all items of constructs are having positive values above 0.5. Therefore, the condition of uni-dimensionality is met for all measurement models.

Table 7. Confirmatory Factor Analysis

\begin{tabular}{|c|c|c|c|c|c|}
\hline Constructs & Items & Loadings & Cronbach's Alpha & CR & AVE \\
\hline \multirow[t]{5}{*}{$\mathrm{IC}$} & IC 1 & 0.809 & 0.881 & 0.913 & 0.677 \\
\hline & IC 2 & 0.835 & & & \\
\hline & IC 3 & 0.867 & & & \\
\hline & IC 4 & 0.816 & & & \\
\hline & IC 5 & 0.786 & & & \\
\hline \multirow[t]{8}{*}{ JP } & JP 1 & 0.812 & 0.931 & 0.943 & 0.674 \\
\hline & JP 2 & 0.815 & & & \\
\hline & JP 3 & 0.779 & & & \\
\hline & JP 4 & 0.826 & & & \\
\hline & JP 5 & 0.859 & & & \\
\hline & JP 6 & 0.849 & & & \\
\hline & JP 7 & 0.759 & & & \\
\hline & JP 8 & 0.861 & & & \\
\hline \multirow[t]{4}{*}{ TD } & TD 1 & 0.823 & 0.794 & 0.867 & 0.625 \\
\hline & TD2 & 0.833 & & & \\
\hline & TD3 & 0.869 & & & \\
\hline & TD4 & 0.610 & & & \\
\hline \multirow[t]{3}{*}{ TT } & TT 1 & 0.852 & 0.840 & 0.904 & 0.758 \\
\hline & TT 2 & 0.896 & & & \\
\hline & TT 3 & 0.863 & & & \\
\hline \multirow[t]{5}{*}{ WE } & WE 1 & 0.772 & 0.845 & 0.890 & 0.619 \\
\hline & WE 2 & 0.780 & & & \\
\hline & WE 3 & 0.823 & & & \\
\hline & WE 4 & 0.836 & & & \\
\hline & WE 5 & 0.718 & & & \\
\hline
\end{tabular}

\section{Validity}

\section{Convergent Validity}

Convergent validity shows the extent to which each item of the latent construct is highly associated with each other. The threshold value for average variance extracted (AVE) should be above 0.05 
and factor loadings of each item should be above 0.7(Hair, Sarstedt, Hopkins \& Kuppelwieser, 2014: Fornell \& Larker 1981). However, factor loading above 0.6 is also acceptable (Barclay et al., 1995). We can see in table 7 above that AVE values are all above threshold values of 0.5 and factor loadings of each item are above 0.7 except TD4 which is 0.6 which is also acceptable.

\section{Discriminant Validity}

As per Fornell Larcker Criterion (FLC), discriminant validity shows that the loadings of indicators for its own latent variable should be higher than loadings of other indicators (Hair et al, 2014). According to the FLC criteria, AVE values should be compared with inter-construct correlation. The diagonal values of AVE Square roots should be higher. Table 5 indicates the square root of AVE values are higher than inter-construct correlation, therefore showing more discriminant validity. Furthermore, table 8 below indicates the values with higher discriminant validity.

Table 8. Fornell Larcker Criterion

\begin{tabular}{llllll}
\hline & IC & JP & TD & TT & WE \\
\hline IC & 0.823 & & & & \\
JP & 0.806 & 0.821 & & & \\
TD & 0.703 & 0.655 & 0.790 & & \\
TT & 0.817 & 0.797 & 0.699 & 0.870 & \\
WE & 0.737 & 0.650 & 0.731 & 0.709 & 0.787 \\
\hline
\end{tabular}

\section{Reliability}

The average variance extracted and (AVE) and composer reliability (CR) are two required assumptions to ensure internal consistency (Blunch, 2008). Moreover, the AVE value should be greater than 0.5 and the CR value should be greater than 0.6 to meet the consistency threshold. Table 9 below represents AVE and CR values for all the constructs.

According to the required assumptions of reliability, AVE values in the table represent values above 0.5 for constructs IC, JP. TD, TT and WE with values $0.68,0.67,0.63,0.75$ and 0.62 respectively. CR values are also above 0.6 showing 0.9 for IC, 0.94 for JP, 0.86 for $\mathrm{Td}, 0.90$ for TT and 0.89 for WE. Therefore, it concludes that the data is highly consistent. In order to confirm CR values, Cronbach's Alpha of each construct is calculated (Nor Azman, 2017). Its value is higher than the cut-off value of 0.7 . 
Table 9. Construct Reliability and Validity

\begin{tabular}{ccccc}
\hline Constructs & Cronbach's Alpha & & $\begin{array}{c}\text { Composite } \\
\text { Reliability }\end{array}$ & $\begin{array}{c}\text { Average Variance } \\
\text { Extracted (AVE) }\end{array}$ \\
\hline & 0.881 & 0.882 & 0.913 & 0.677 \\
JP & 0.931 & 0.932 & 0.943 & 0.674 \\
TD & 0.794 & 0.820 & 0.867 & 0.625 \\
TT & 0.840 & 0.841 & 0.904 & 0.758 \\
WE & 0.845 & 0.852 & 0.890 & 0.619 \\
\hline
\end{tabular}

\section{Predictive Relevance of the Model}

The extent of this change is classified into three levels as low, moderate and substantial. The cutoff points for these levels are less than 0.2 , between 0.3 and 0.6 and above 0.6 respectively (Sanchez, 2013).

Table 10. Predictive Power of Construct

\begin{tabular}{lcc}
\hline & R Square & Q square \\
\hline JP & 0.636 & 0.409 \\
TT & 0.706 & 0.513 \\
\hline
\end{tabular}

\section{Effect Size}

As per the criteria of Hair et al. (2014), the effect size is categorized into three levels: strong, moderate, and poor with values $0.35,0.15$ and 0.2 respectively. The effect size of the relationship between IC and TT is strong with the value of 0.4, the effect size relationship between TD and TT is poor. Furthermore, the relationship between TT and JP is very strong with a value of 1.744 and between WE and TT is poor with a value of 0.28 .

Table 11. Effect Size

\begin{tabular}{cc}
\hline Constructs Linkage & F Square \\
\hline IC-TT & $\mathbf{0 . 4 5 2}$ \\
TD-TT & 0.046 \\
TT-JP & $\mathbf{1 . 7 4 4}$ \\
WE-TT & 0.028 \\
\hline
\end{tabular}

\section{Model Fitness}

The Model below the fitness table indicates SRMR and NFI values as significant with SRMR at less than 0.1 , that is 0.05 and NFI value as 0.8 . Moreover, values of (d_ULS) are 0.9 and d-G1 and d_G2 are 0.60 and 0.52 , respectively. Hence, the values are meeting the assumptions, so the regression model has strong fitness. 
Table 12. Model Fitness

\begin{tabular}{ccc}
\hline & Saturated Model & Estimated Model \\
\hline SRMR & 0.055 & 0.071 \\
d_ULS & 0.989 & 1.655 \\
d_G1 & 0.607 & 0.671 \\
d_G2 & 0.522 & 0.568 \\
NFI & 0.841 & 0.832 \\
\hline
\end{tabular}

Figure 2. Structural Model

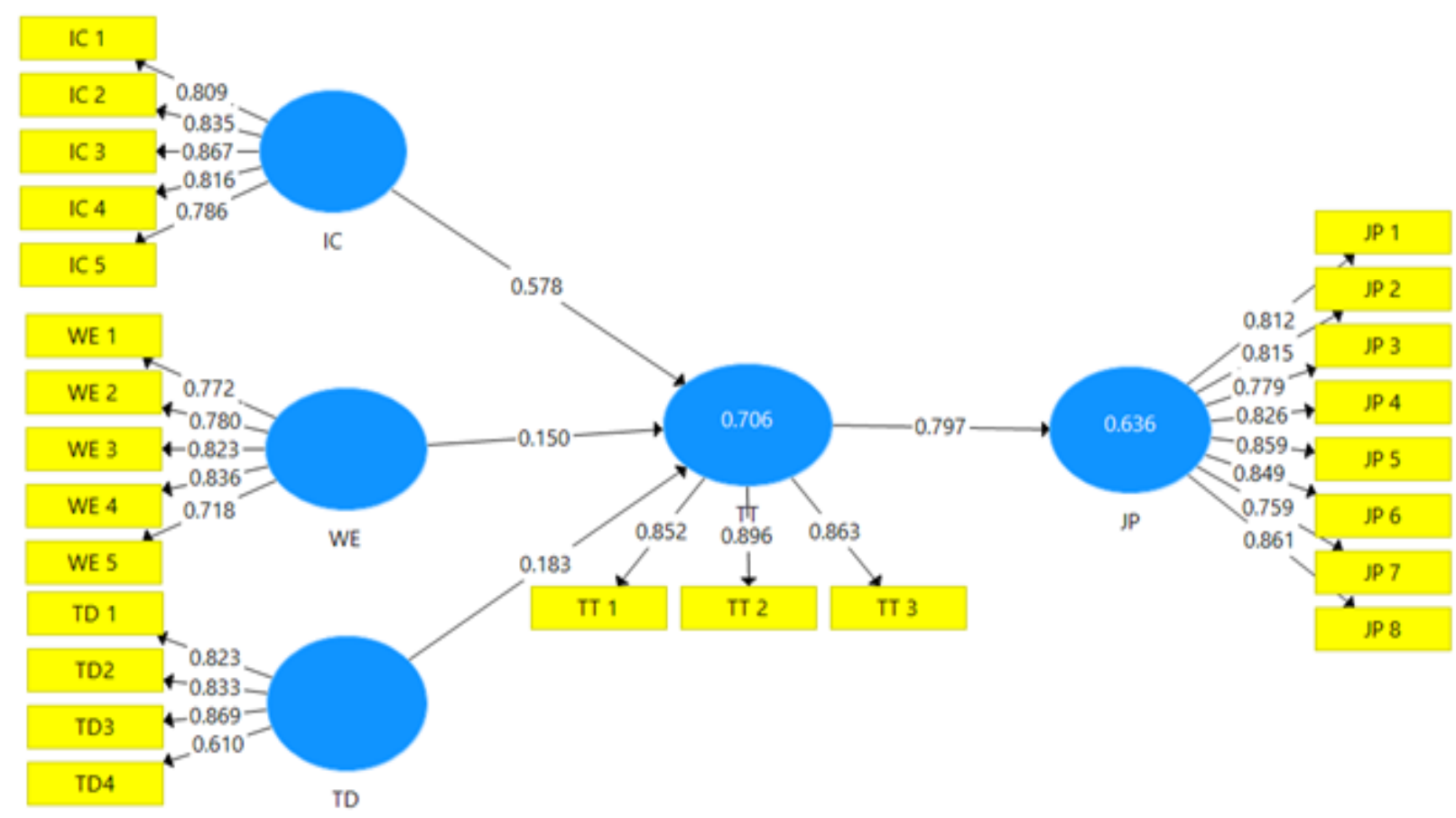

Note: IC: individual characteristics, WE: work Environment, TD: Training Design, TT: Training Transfer, JP: Job Performance.

\section{Hypothesis Testing}

The table below enables the researcher to test the first four hypotheses showing direct effect with the help of path coefficients with bootstrapping values.

Table 13. Hypothesis Testing (Direct Effect)

\begin{tabular}{lllllll}
\hline Hypothesis & $\begin{array}{l}\text { Original } \\
\text { Sample } \\
(\mathbf{O})\end{array}$ & $\begin{array}{l}\text { Sample } \\
\text { Mean (M) }\end{array}$ & $\begin{array}{l}\text { Standard } \\
\text { Deviation } \\
\text { (STDEV) }\end{array}$ & $\begin{array}{l}\text { T Statistics } \\
(\mid \mathbf{O} / \text { STDEV })\end{array}$ & P Values & Decision \\
\hline H1:IC -> TT & 0.578 & 0.580 & 0.058 & 10.039 & 0.000 & Accepted \\
H4:WE -> TT & 0.150 & 0.155 & 0.066 & 2.262 & 0.024 & Accepted \\
H2:TD -> TT & 0.183 & 0.176 & 0.060 & 3.050 & 0.002 & Accepted \\
H3: TT -> JP & 0.797 & 0.799 & 0.033 & 24.481 & 0.000 & Accepted \\
\hline
\end{tabular}




\section{H1: There is a significant positive relationship between individual characteristics and training transfer.}

Table 13 above confirms the strong relationship between individual characteristics and Training transfer therefore this hypothesis is accepted. The value of the path coefficient is 0.57 meeting the Threshold value of the path coefficient is greater than 0.1. The value of standard deviation is 0.058 which depicts that the data is less deviated and reliable. T-Statistics is 10.03 at a cut-off point greater than 1.96 showing a strong positive relationship between both constructs. Moreover, the relationship is significant at a p-value of 0.00 less than the threshold value of 0.05 . Therefore, it is concluded that there is a significant positive relationship between individual characteristics and training transfer.

Hypothesis 1 involves the direct impact of individual characteristics on training transfer. Results have confirmed the hypothesis by showing statistical significance Also these findings are also compatible with past research. According to the findings of Velada (2007), the independent variable of Individual characteristics is positively related to training transfer. Moreover, when trainings believe in their abilities and when they retain learned skills, they are most likely to transfer them on the job (Velada, Caetano, Michel, \& Lyons, 2007).

H2: There is a significant positive relationship between work environment and training transfer at the workplace.

The second hypothesis is accepted based on the beta coefficient $0.1, T$-statistics 2.26 and p-value 0.04 , meeting the threshold values of beta coefficient as greater than 0.1 , T-statistics as greater than 1.96, and the p-value less than 0.05 , respectively. Moreover, the standard deviation is 0.06 showing that the data is less deviated. Therefore, it is concluded that there is a significant positive relationship between work environment and training transfer. Thus, hypothesis 2 suggests positive a relationship of the work environment with the transfer of training. The quantitative analysis findings of the research under study are confirming the hypothesis by showing a positive and significant relationship of both variables. The results are consistent with the past research studies. A favourable environment leads to successful training transfer at the workplace (Çifci, 2014). In the training research, the work environment factor was ignored initially by focusing primarily on trainee characteristics and training design. Moreover, its positive impact of training transfer and other organizational outcomes enhances its standing. 
When a conductive work environment is provided to the employees with proper feedback from the management and supervisor support, employees are likely to transfer skills. According to Velada et al. (2007) work environment with reference to supervisor support and others feedback regarding the employee performance after training has a positive impact on training transfer at the workplace. H3: There is a significant positive relationship between training design and training transfer to the workplace.

Table 12 confirms a strong positive relationship between training design ad train8ng transfer, Therefore this hypothesis is accepted. The value of the path coefficient is 0.183 which is meeting the threshold value of beta $>0.01$. The standard deviation is 0.06 showing the data as less deviated so more reliable- statistics is 3.05 which is greater than the cut-off point 1.96 showing a positive relationship between both constructs. Moreover, the p-value is significant with a value of 0.002 at less than the 0.5 threshold value. Therefore, it is said that there is a significant positive relationship between training design and training transfer.

Hypothesis 3 involves the impact of training design on training transfer. The results of the research under study are confirming the hypothesis by indicating the positive and significant impact of training design on training transfer. The finding of this hypothesis is also consistent with the earlier research. Training design has a positive impact on training transfer (Çifci, 2014). Training design in terms of its application and relevance of contents to the real workplace is directly related to training transfer (Velada, 2007).

H4: There is a significant positive relationship between training transfer and job performance.

This hypothesis is also accepted based on the fact that there exists a strong positive relationship between Training design and training transfer p- value is significant with a value 0.00 less than the threshold value of less than 0.05.T- statistics is 24.4 far above the threshold value of 1.96. Data is less deviated with a value of 0.033 sense reliable. The value of the path coefficient is 0.797 above the cut-off point of 0.01 . Therefore it is concluded that there is a significant positive relationship between Training Transfer and Job performance.

Hypothesis 4 involves the impact of training transfers on job performance. The quantitative analysis findings of the research under the study are confirming the hypothesis by showing a positive and significant relationship of both variables. Studies have evidenced that training has 
positive outcomes on employee output that consequently leads to improved individual's job performances.

When the trainees learn a particular skill from the training and successfully implement and practice it in the real workplace, then positive outcomes are achieved where job performance is one of the core outcomes. Without the successful transfer of training skills job performance cannot be improved.

Table 14. Hypothesis Testing (Indirect effect)

\begin{tabular}{lllllll}
\hline Hypotheses & $\begin{array}{l}\text { Original } \\
\text { Sample } \\
(\mathbf{O})\end{array}$ & $\begin{array}{l}\text { Sample } \\
\text { Mean (M) }\end{array}$ & $\begin{array}{l}\text { Standard } \\
\text { Deviation } \\
(\text { STDEV) }\end{array}$ & $\begin{array}{l}\text { T Statistics } \\
(\mid \mathbf{O} / \text { STDEV|) }\end{array}$ & P Values & Decision \\
\hline H5:IC -> TT -> JP & 0.461 & 0.463 & 0.053 & 8.772 & 0.000 & Accepted \\
H6:TD -> TT -> JP & 0.146 & 0.141 & 0.048 & 3.035 & 0.003 & Accepted \\
H7:WE -> TT -> JP & 0.119 & 0.124 & 0.053 & 2.246 & 0.025 & Accepted \\
\hline
\end{tabular}

H5: There is a significant relationship between individual characteristics and job performance when training transfer mediates the relationship.

Table 14 indicates the significant mediation effect of the Training Transfer between the relationship of individual characteristics and job performance. Based on the results (path coefficient $=0.461$, standard deviation 0.053 , T statistics 8.79 and p-value 0.000 ) hypothesis 5 is accepted. . The value of path coefficient is 0.461 which is meeting the threshold value of beta > 0.01. Standard Deviation is 0.053 showing the data as less deviated so more reliable- statistics is 9.79 which is greater than the cut-off point 1.96 showing a positive relationship between both constructs. Moreover, the p-value is significant with a value of 0.000 at less than 0.5 threshold values. Therefore, it is said that there is Training Transfer mediates the relationship between individual characteristics and job performance.

This hypothesis is related to the indirect impact of an individual's characteristics on job performance when training transfer mediates the relationship. Results of the research under study are confirming these relationships by indicating significant values and model fit. There are fewer researchers who did work defining this relationship. Moreover, little evidence is found in the literature where research has been done on academic staff and other areas but no evidence was found on the development sector. When training transfer mediates the relationship then Individual characteristics have a positive effect on job performance (Obaid et al., 2016). Based on the argument we can say that this hypothesis is supported by past research. Training transfer depends 
on other factors as well. Involved factors are Work environment and training design along with individual characteristics as per Baldwin and Ford's model (1988). The transfer is the third level in the Kirkpatrick's model of training evolution (2011) after the levels of reaction and learning. Moreover, outcome is the last level .based on the argument we conclude that training transfer leads to positive outcomes of job performance.

H6: There is a significant relationship between work environment and job performance when training transfer mediates the relationship.

Table 14 indicates a significant mediation effect of the training transfer between the relationship of work environment and job performance. Based on the results, (path coefficient $=0.146$, standard 15 deviation 0.048 , T statistics 3.035 and p-value 0.003 ) hypothesis 6 is accepted. The value of the path coefficient is 0.146 which is meeting the threshold value of Beta $>0.01$. The standard deviation is 0.048 showing the data as less deviated so more reliable. T- Statistics value is 3.035 which are greater than cut-off point 1.96 showing a positive relationship between both constructs. Moreover, the p-value is significant with a value of 0.003 at less than 0.5 threshold values. Therefore it is said that training transfer mediates the relationship between work environment and job performance.

The indirect impact of the work environment on job performance is hypothesized when training transfer mediates the relationship. PLS results of the study also confirm this relationship. When training transfers mediated the relationship then work environment impacts positively on job performance (Obaid et al., 2016). Trainees with a favourable approach towards the organisation and their job are the ones to achieve positive outcomes than those trainees, who have a negative approach.

H7: There is a significant relationship between training design and job performance when transfer training mediates the relationship.

The table above represents the significant mediation effect of the training transfer between the relationship of training design and job performance. Based on the results (path coefficient $=0.119$, standard deviation 0.053, T statistics 2.246 and p-value 0.025$)$, hypothesis 7 is accepted. The value of the path coefficient is 0.119 which is meeting the threshold value of beta $>0.01$. Similarly, the standard deviation value is 0.053 , showing the data is less deviated thus is more reliable. TStatistics value is 2.246 which is greater than the cut-off point of 1.96 showing a positive 
relationship between both constructs. Moreover, the p-value is significant with a value of 0.025 which is less than the threshold value. Therefore, it is said that training transfer mediates the relationship between training design environment and job performance.

The mediating effect of training transfer on the relationship between training design and job performance is statistically significant by indicating a positive relationship (Obaid et al., 2016). Hypothesis 7 asserts the mediating relationship is confirmed by the PLS results by depicting significant results. Past research studies have revealed that training trainee has a positive intention to transfer training skill when training contents are realistic and close to the actual workplace, in this way trainees not only recall training contacts but also practice them in the actual workplace.

\section{RESEARCH IMPLICATIONS}

This research attempted to investigate the impact of certain factors on training transfer that leads to job performance. Among these factors, individuals' characteristics were taken as the first factor, with indicators of self-efficacy and training retention. The second factor was the work environment that involved indicators of feedback and supervisory support. Lastly, the third factor, training design, was validated from the previous literature and was found that these factors are strong predictors of training transfer. Furthermore, impact on job performance was validated from the results and quantitative analyses were conducted in the context of Pakistan's development sector whereas previous studies were conducted in different regional and industrial contexts.

In most organizations, stakeholders involve UN agencies and other NGOs where extensive training is provided to their diverse workforces. Hence the transfer of training and its impact on workplace outcomes is analysed based on the past or current training experiences of the employees. Study findings suggest that these factors are directly linked to training transfer at the workplace and when employees are successfully transferring skills, it leads to positive outcomes of job performance. Therefore, study findings are implacable to this sector specifically and can be generalised to other sectors as well. Since this study involves training transfer skills at the actual workplace to improve job performance, therefore supervisors must ensure training retention and transfer by providing a supportive environment through reinforcement and motivation. Besides, the HR departments in the development sector should develop appropriate strategies for training retention and transfer, however, before designing a training program focus should be made on strong training content and trainer skills. More knowledge of job content leads to increase concern in the performance of circadian job responsibilities (Ellstrom \& Ellstrom, 2014). The literature demonstrates that self- 
efficacy has a strong relation with training transfer (Quinones, 1995). Similarly, training retention is another important factor that leads to the successful transfer of training.

\section{CONCLUSION}

This study was designed to investigate the direct impact of training factors including training design, work environment and trainee characteristics on training transfer at the workplace and indirect impact of training factors on job performance when training trainer mediated the relationship. Results of PLS-SEM indicated a positive relationship by confirming direct and indirect hypotheses. Therefore all hypotheses are accepted. The results of the research under study support the existing literature in the field of training transfer and job performance. The theoretical model of the study shows direct and indirect relationships. The model fitness indices are depicting robustness. Therefore, our conceptual model was outstripped and well fitted. Moreover, individuals' characteristics are showing a significant direct relationship with training transfer and a significant indirect effect on job performance. Similarly, the work environment directly leads to training transfer and indirectly leads to job performance. Training design also indicates a significant direct and indirect relationship with training transfer and job performance respectively.

According to the argument based on the results of this study, evidence of a similar relationship has existed between latent constructs. Past studies have focused on the impact of training on the transfer of training at different training stages like pre-training, in-training and post-training. But this study focused on the gap between training received and implementation and its impact on job performance. Although the respondents of the research were those who had prior training experience throughout their jobs experience and it was not specific to any training stage. The strength of this research is the responses from the development sector with their positive interest in the phenomena which leads to a constructive response where middle and upper-level employees were selected. Therefore, this research fills the gap.

Moreover, this study has certain limitations. Although the researcher has received quality data from only interested respondents but collecting a large pool of data was a hindrance due to accessibility and privacy issues. Also, as most employees of NGO's get limited contracts for the short term thus collecting information from employees with long term job experience with the same NGOs was a constraint. Additionally, as NGOs are funding based organizations, due to low 
funding many such organizations are downsizing, thus access to a larger pool of long-term working employees was a difficult target to meet.

\section{RECOMMENDATIONS}

The current study was conducted on various organisations in the development sector in Pakistan. There are various recommendations not only for the specified sector but also for other private and public sector organizations where little to diversified trainings are provided to employees. The results show a strong positive relationship of individuals' characteristics with training transfer and a strong positive relationship of training transfer with job performance. Therefore, managers must pay attention to enhancing individuals' self-efficacy and training retention to transfer learning comes from the training at the workplace. Moreover, attention should be paid to ensuring training transfer to enhance employee productivity that is linked with organizational performance.

Job performance based on this research and past research can be improved only when successful training skill transfer has ensued, therefore training contents should be selected carefully to have close relevance with the job i.e. employees in the relative departments should be given training specifically relevant to their department according to their job roles and demands. Similarly, staff preparedness should be ensured by working proactively. Moreover, employees should be trained to respond to emergencies as mostly in NGO's they have to deal with crises in many cases. Lastly, it is emphasized that job performance is linked with overall organizational objectives therefore training objectives should be associated with the organizational goals. 


\section{REFERENCES}

Alias, S. A., Ong, M. H. A., Rahim, A. R. A., \& Hassan, R. (2019). The Role of Training Design Factors in Influencing Training Effectiveness among Public Service Employees. International Journal of Academic Research in Business and Social Sciences, 9(5), 898 - 913.

Alton, L. (2017). Why corporate culture is becoming even more important. USA: Forbes Media $L L C$.

Bai, Y., li, j., Bai, Y., \& Ma, W. (2018). Development and validation of a questionnaire to evaluate the factors influencing training transfer among nursing professionals. BMC Health Services Research. Doi: https://doi.org/10.1186/s12913-018-2910-7

Bell, E., Bryman, A., \& Harley, B. (2018). Business research methods. Oxford University Press.

Bhatti, M. A., Battour, M. M., Sundram, V. P. K., \& Othman, A. A. (2013). Transfer of training: does it truly happen? An examination of support, instrumentality, retention and learner readiness on the transfer motivation and transfer of training. European Journal of Training and Development.

Bhuiyan, M.S.J. (2017). Influence of individual characteristics, organizational support system and learning organizational practices in post-program transfer of training: A study on management development programs of Bangladesh Civil Service. International Journal of Human Resource Studies, 7(3), 23-48

Bhuvanaiah, T., \& Raya, R. P. (2015). Mechanism of improved performance: Intrinsic motivation and employee engagement. SCMS Journal of Indian Management, 12(4), 92-97.

Blume, B. D., Ford, J. K., Baldwin, T. T., \& Huang, J. L. (2010). Transfer of training: A metaanalytic review. Journal of Management, 36(4), 1065-1105.

Blunch, N. J. (2008). Introduction to Structural Equation Modelling Using SPSS and AMOS. Doi: https://dx.doi.org/10.4135/9781446249345

Bukar, A. A., \& Ibrahim, U. A. (2021). Investigating the Impact of Risk Management on Project Performance in Construction Industry: Evidence from Nigeria. Science Journal of Business and Management, 9(3), 224.

Çifci, O. S. (2014). Transfer system factors on training transfer with regard to trainee characteristics and contextual variables: a case of the Central Bank of the Republic of Turkey. 
Crouse, P., Doyle, W., \& Young, J. D. (2011). Workplace learning strategies, barriers, facilitators and outcomes: A qualitative study among human resource management practitioners. Human Resource Development International, 14(1), 39-55.

Curry, D., McCarragher, T., \& Dellmann-Jenkins, M. (2005). Training, transfer, and turnover: Exploring the relationship among transfer of learning factors and staff retention in child welfare. Children and Youth Services Review, 27(8), 931-948.

Dermol, V., \& Čater, T. (2013). The influence of training and training transfer factors on organizational learning and performance. Personnel Review.

Ellström, E., \& Ellström, P. E. (2014). Learning outcomes of a work-based training programme: The significance of managerial support. European journal of training and development. 187189. doi:10.1108/EJTD-09-2013-0103

Fatima, M., \& Siddiqui, D. A. (2019). Factors Affecting Transfer of On-The-Job Training at $\begin{array}{lllll}\text { workplaces } & \text { in } & \text { 3510595.doi: }\end{array}$ http://dx.doi.org/10.2139/ssrn.3510595

Fogaça, N., Rego, M. C. B., Melo, M. C. C., Armond, L. P., \& Coelho Jr, F. A. (2018). Job performance analysis: scientific studies in the main journals of management and psychology from 2006 to 2015. Performance Improvement Quarterly, 30(4), 231-247.

Fornell, C., \& Larcker, D. F. (1981). Evaluating structural equation models with unobservable variables and measurement error. Journal of Marketing Research, 18(1), 39-50. doi: https://doi.org/10.2307/3151312

Friedman, S., \& Ronen, S. (2015). The effect of implementation intentions on transfer of training. European Journal of Social Psychology, 45(4), 409-416.

Ghosh, P., Satyawadi, R., Joshi, J. P., Ranjan, R., \& Singh, P. (2012). Towards more effective training programmes: A study of trainer attributes. Industrial and commercial training. 44(4), 194- 202.

Grossman, R., \& Salas, E. (2014). Game-and Simulation-Based Approaches to Training. The Wiley Blackwell handbook of the psychology of training, development, and performance improvement, 205-223. 
Henseler, J., Ringle, C. M.\& Sarstedt, M. (2015). A new criterion for assessing discriminant validity in variance-based structural equation modeling. Journal of the Academy of Marketing Science, 43(1), 115-135. https://doi.org/10.1007/s11747-014-0403-8

Holton III, E. F. (2005). Holton's evaluation model: New evidence and construct elaborations. Advances in developing human resources, 7(1), 37-54. Doi: https://doi.org/10.1177/1523422304272080

Holton, E. F., \& Baldwin, T. T. (2003). Making transfer happen: An action perspective on learning transfer systems. Improving learning transfer in organizations, 3(5).

Jackson, L. (2014). The work engagement and job performance relationship: Exploring the mediating effect of trait emotional intelligence. San José State University.

Kia, N., \& Ismail, I. B. (2013). The relationship between Environmental Characteristics and Training Transfer. International Journal of Business and Social Science, 4(12).

Kilbrink, N., Bjurulf, V., Baartman, L. K., \& de Bruijn, E. (2018). Transfer of learning in Swedish technical vocational education: Student experiences in the energy and industry programmes. Journal of Vocational Education \& Training, 70(3), 455-475. Doi: https://doi.org/10.1080/13636820.2018.1437064

Kim-Soon, N., Rahman, A., \& Ahmed, M. (2014). E-service quality in higher education and frequency of use of the service. International Education Studies, 7(3), 1-10.

Kirkpatrick, D., \& Kirpatrick, J. D. (2011). The Kirkpatrick four levels. Kirkpatrick Partners.

Leonardo, M. L. M. (2015). Lost in Transfer: How Training Participant Narratives Reveal Training Transfer Experiences. ProQuest LLC 78-1-3031-7956-3

Ma, C. C., \& Chang, H. P. (2013). Training transfer in the Taiwanese hotel industry: Factors and outcomes. Social Behavior and Personality: An International Journal, 41(5), 761-77 DOI: https://doi.org/10.2224/sbp.2013.41.5.761

Marr, B. (2017). The 10 biggest challenges businesses face today (and need consultants for). Growth and operations management consultants. www.hiscox.co.uk

Na-Nan, K., \& Sanamthong, E. (2019). Self-efficacy and employee job performance: Mediating effects of perceived workplace support, motivation to transfer and transfer of training. International Journal of Quality \& Reliability Management. 
Nitzl, C., Roldan, J. L., \& Cepeda, G. (2016). Mediation analysis in partial least squares path modeling: Helping researchers discuss more sophisticated models. Industrial management \& data systems.

Nor Azman, A. H. (2017). Structural Equation Modelling (SEM): Confirmatory Factor Analysis (CFA). Research Gate. doi:10.13140/RG.2.2.25615.38565.

Obaid, T. (2014). The role of key factors of training transfer on employee's job performance: A review. European Scientific Journal June. 1857 -7881.

Obaid, T. F., Zainon, M. S., Eneizan, B. M., \& Wahab, K. A. (2016). The mediating of training transfer between pre training factors and job performance. Review of Public Administration and Management, 400(3786), 1-11.

Pandey, J. (2018). Factors affecting job performance: an integrative review of literature. Management Research Review. 42(2), 263-289. Doi: https://doi.org/10.1108/MRR$\underline{02-2018-0051}$

Polit, D. F., \& Beck, C. T. (2010). Generalization in quantitative and qualitative research: Myths and strategies. International journal of nursing studies, 47(11), 1451-1458.

Putter, S. E. (2013). Making training stick: a close examination of how trainee readiness, supervisor support, and practice foster transfer in a mobile technology-based training program (Doctoral dissertation, Colorado State University).

Quinones, M.A. (1995) Pre-training context effects: Training assignment as feedback. Journal of Applied Psychology, 80, 226-238. http://dx.doi.org/10.1037/0021-9010.80.2.226

Qureshi, M. A., \& Hamid, K. (2017). Impact of supervisor support on job satisfaction: A moderating role of fairness perception. International Journal of Academic Research in Business and Social Sciences, 7(3), 235-242. DOI: 10.6007/IJARBSS/v7-i3/2729

Saleh, B. A. N. (2012). Factors affecting transfer of training within the work environment from the perception of workers in Palestinian Government Hospitals (Doctoral dissertation).

Sarstedt, M., Ringle, C. M., \& Hair, J. F. (2017). Partial least squares structural equation modeling. Handbook of market research, 26(1), 1-40. Doi: https://doi.org/10.1080/09585192.2017.1416655

Saunders, M., Lewis, P., \& Thornhill, A. (2009). Research methods for business students. Pearson education. 
Shi, J., \& Liu, X. (2015). Empirical Study of Factors Affecting Training Transfer of Grassroots Employees in Petroleum Enterprises. The Open Petroleum Engineering Journal,8(1). Doi: $10.2174 / 1874834101508010368$

Siddiqui, T., \& Iqbal, M. A. (2021). Six Sigma Practices on the Perceived Betterment of Organization Performance. Journal of Entrepreneurship, Management, and Innovation, 3(1), 77-96. https://doi.org/10.52633/jemi.v3i1.52

Starks, M. P. (2019). The Impact of Transfer of Training within Organizations (Doctoral dissertation, The Chicago School of Professional Psychology).

Svyantek, D. J., Goodman, S. A., Benz, L. L., \& Gard, J. A. (1999). The relationship between organizational characteristics and team building success. Journal of Business and Psychology, 14(2), 265-283.

Tracey, D. H., \& Mandel, L. (2012). Lenses on Reading: An Introduction to Theories and Models\| Guilford Press.

Turi, J. A., Javed, Y., Bashir, S., Khaskhelly, F. Z., Shaikh, S., \& Toheed, H. (2019). Impact of Organizational Learning Factors on Organizational Learning Effectiveness through Mobile Technology. Quality-Access to Success, 20(171).

Velada, R., Caetano, A., Michel, J. W., Lyons, B. D., \& Kavanagh, M. J. (2007). The effects of training design, individual characteristics and work environment on transfer of training. International journal of training and development, 11(4), 282-294.

Wenzel, R., \& Cordery, J. (2014). Training transfer research: A manager's guide and bibliography. Woodworth, R. S., \& Thorndike, E. L. (1901). The influence of improvement in one mental function upon the efficiency of other functions. (I). Psychological Review, 8(3), 247.

This is an open-access article distributed under the Creative Commons Attribution License 4.0

\section{(c) (1)}

